\title{
Cavity preparation machine for the standardization of in vitro preparations
}

\begin{abstract}
Carlos José Soares(a)
Rodrigo Borges Fonseca ${ }^{(a)}$

Henner Alberto Gomide(b)

Lourenço Correr-Sobrinho(c)
\end{abstract}

(a) Professors, Operative Dentistry and Dental Materials Department, Dental School,

Federal University of Uberlândia.

(b) Full Professor, Department of Mechanical Engineering, Biomechanics Group, Mechanical Engineering School, Federal University of Uberlândia.

(c) Professor, Department of Dental Materials, Piracicaba Dental School, State University of Campinas.
Corresponding author:

Carlos José Soares

Faculdade de Odontologia

Universidade Federal de Uberlândia

Av. Pará, n. 1720

Uberlândia - MG - Brazil

CEP: 38400-902

E-mail: carlosjsoares@umuarama.ufu.br
Abstract: Several in vitro studies employ the confection of cavity preparations that are difficult to standardize by means of manual high speed handpieces. This study presents the development of a cavity preparation machine designed to standardize in vitro cavity preparations. A metal base of $25 \mathrm{~mm} \times 25 \mathrm{~mm} \times 4 \mathrm{~mm}$ (length $\mathrm{x}$ width $\mathrm{x}$ height) was coupled to a small mobile table which was designed to be able to move by means of two precision micrometers (0.01-mm accuracy) in the horizontal directions (right-left, and back-front). A high speed handpiece was coupled to a metallic connecting rod which had an accurate dial indicator enabling control of the vertical movement. The high speed handpiece is also able to move $180^{\circ}$ around its longitudinal axis and $360^{\circ}$ around its transversal axis. The suggested cavity preparation machine precisely helps in the standardization of cavity preparations for in vitro studies.

Descriptors: Dental cavity preparation; Laboratory techniques and procedures; Laboratory equipment. 


\section{Introduction}

In vitro tests, within their limits, provide some idea of the behavior of restorations in simulated clinical situations. ${ }^{1}$ Thus, it seems important to determine the forces that may induce fracture of such restorations and suggest a preparation that will provide greatest resistance to fracture or better marginal accuracy. ${ }^{2-5}$ Several studies have assessed the influence of cavity preparation designs on fracture resistance of restored teeth, ${ }^{2,4-9}$ degree of polymerization of composite resin and resin cements, marginal and intaglio adaptation of indirect restorations, ${ }^{4,5,10,11}$ adhesive bond strength of restorations, ${ }^{12}$ transference of stresses to tooth structure, ${ }^{13,14}$ cuspal deflection and microleakage. ${ }^{15}$ Some of these studies have employed manual preparation of the cavities with high speed handpieces ${ }^{8,16,17}$ but in some instances it is not mentioned how were the cavity dimensions standardized, ${ }^{18}$ although the non-standardization could affect the reliability of the results. Etemadi et al. ${ }^{18}$ (1999) assessed the reproducibility of a previous established tooth preparation design for posterior resin-bonded porcelain restorations, which should be manually reproduced by specialists, and found a great difference in the preparations made by different individuals.

According to the degree of accuracy, the method of standardization may use scaled periodontal probes, ${ }^{19}$ analogical calipers, ${ }^{15,20}$ digital calipers, ${ }^{21}$ measuring microscopes, ${ }^{22}$ precision electronic micrometers, ${ }^{19,23}$ handpieces mounted on dental surveyors ${ }^{24}$ and cavity preparation machines equipped with precision micrometers. ${ }^{13,14}$ The most inaccurate methods employ manual measurement of cavities after or during preparation, while the most accurate ones use instant digital measurement during preparation. According to Sá, Gabrielli ${ }^{25}$ (1987), the first cavity preparation machine for in vitro studies was created by the same authors in 1975 . They used an optical microscope with some adaptations for attaching a high speed hand piece and the sample to be prepared. It seems of great importance to search for a way to standardize cavity preparations, especially for in vitro tests. Although several studies have used cavity preparation machines or other types of devices, none of them describe how they work, nor do they present the mechanical instruments used for their construction. The aim of this study was to suggest a cavity preparation machine designed to standardize in vitro cavity preparations.

\section{Material and Methods Cavity preparation machine description}

The cavity preparation machine, as demonstrated in Figure 1, was developed at the Dental, and Mechanical Engineering Schools, Federal University of Uberlândia, MG, Brazil. The principal components of the entire device are two precision mechanical micrometers and one dial indicator with a $0.01 \mathrm{~mm}$ accuracy (Mitutoyo Am. Corp., Ontario, Canada), one high-speed hand piece (Kavo, Joinville, SC, Brazil), a stainless steel base $(25.0 \mathrm{~mm} \times 25.0 \mathrm{~mm}$ $\mathrm{x} 4.0 \mathrm{~mm}$ - length $\mathrm{x}$ width $\mathrm{x}$ height) with four adjustable support feet, a fixed stainless steel table $(10.0 \mathrm{~mm} \times 10.0 \mathrm{~mm} \times 5.0 \mathrm{~mm}$ - length $\mathrm{x}$ width $\mathrm{x}$ height), a mobile table which is coupled to two precision micrometers and a metal holder to keep the prepared tooth steady.

It is necessary to use a stainless steel base with at least $4 \mathrm{~mm}$ in height in order to enable the attachment of the other components (Figure 1A). More than $4 \mathrm{~mm}$ is not necessary and will make it too heavy. Also, $25.0 \mathrm{~mm}$ x $25.0 \mathrm{~mm}$ (length $\mathrm{x}$ width) seems important to offer enough stability to the machine when it is working. Four adjustable feet (Figure $1 \mathrm{~B}$ ) were added to this base in order to allow correct adaptation to the surface where the machine is placed. These feet are connected to the base by means of threads and when they are screwed they adapt to the surface. Irrespective of this possibility it is advisable to use the machine over a plane and flat surface to avoid any risk of visual imperfections due to inclination. The next step is to attach a fixed table (Figure 1C) with $10.0 \mathrm{~mm} \times 10.0 \mathrm{~mm} \times 5.0 \mathrm{~mm}$ (length $\mathrm{x}$ width $\mathrm{x}$ height) to this metallic base. This table is a support to the mobile table and it has a lateral perforation which enables a connection with the first micrometer (Figure 1F).

Two vertical smooth stainless steel connecting rods $(25.0 \mathrm{~mm}$ in height $)$ are fixed at the left-back corner of the base. These connecting rods should keep an interfacial distance of around $5.0 \mathrm{~mm}$. Exactly at the center of these connecting rods there is a 


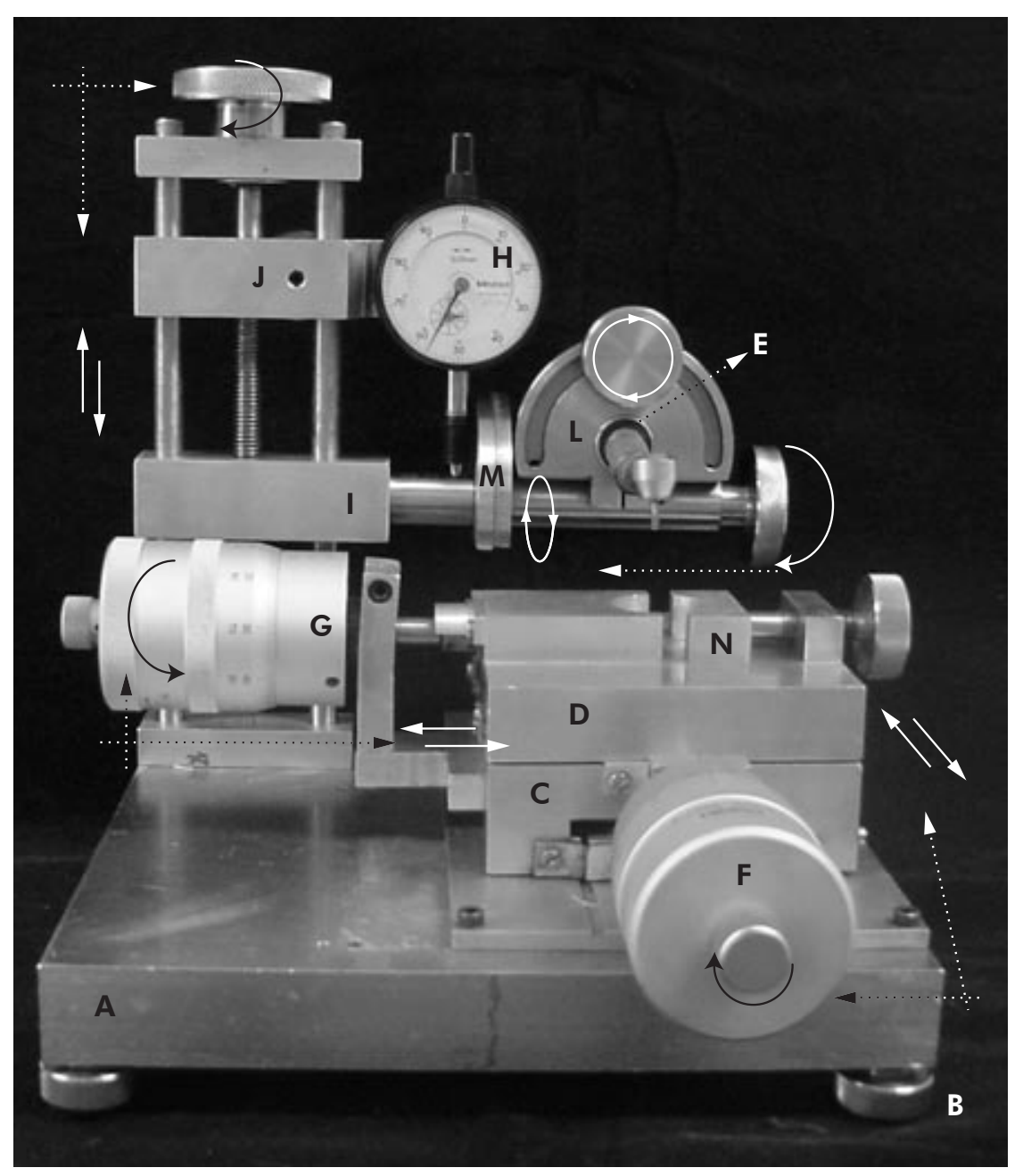

Figure 1 - Cavity preparation machine. Arrows indicate the direction of movements. (A) Stainless steel base $(25.0 \mathrm{~mm} \times 25.0$ $\mathrm{mm} \times 4.0 \mathrm{~mm}$ - length $\mathrm{x}$ width $\mathrm{x}$ height). (B) Adjustable support feet. (C) Fixed stainless steel table $(10.0 \mathrm{~mm} \times 10.0 \mathrm{~mm} \times 5.0 \mathrm{~mm}$ - length $x$ width $x$ height). (D) Mobile stainless steel table which is coupled to two precision micrometers and a metal holder to keep the prepared tooth steady; according to the arrows it is possible to see how this table moves in the front-back and right-left directions. (E) High speed handpiece (HS) with rigid attachment. (F) Micrometer that enables movement in the front-back direction. (G) Micrometer that enables movement in the right-left direction. (H) Dial indicator that controls the quantity of vertical movement of the HS (see Figure 2). (I) Inferior horizontal connecting rod, which is attached to the $\mathrm{HS}$ and has a screwed perforation in order to enable vertical movement. (J) Superior horizontal connecting rod, which is attached to a micrometer enabling control of vertical movement. (L) metal device with rigid attachment to the HS; it enables movement $180^{\circ}$ around its longitudinal axis and $360^{\circ}$ around its transversal axis (see white arrows). (M) metal device with surface marks to guide movements of the HS around its own axis. (N) Metal holder; it maintains the tooth to be prepared in a steady condition.

$20.0 \mathrm{~mm}$-high screw which goes through two other horizontal connecting rods (Figure $1 \mathrm{I} ; \mathrm{J}$ ). The central perforation of the superior horizontal connecting rod (Figure 1J) should be large enough to permit free passage of the screw. On the other hand, the inferior horizontal connecting rod (Figure 1I) should have a threaded central perforation which will enable upward and downward controlled movements when the screw is screwed. On the back of the superior connecting rod there is a screw designed to hold it in position when there is any movement on the inferior connecting rod. This is necessary because one micrometer (Figure $1 \mathrm{H}$ ) is attached to the superior connecting rod and it will be responsible for showing how many millimeters the inferior connecting rod is moving upward or downward. This micrometer has a metallic spring which contacts the inferior connecting rod; when there is any vertical movement the spring is stretched or compressed and registers movement in micrometers. Figure 2 shows the inferior horizontal connecting rod moving $2.5 \mathrm{~mm}$ downward; as it moves downward less load is applied to the micrometer spring and then it registers the extension of the movement.

A high speed handpiece (HS) is attached to the inferior horizontal connecting rod, which controls its vertical movement, as described before. The HS has a rigid attachment (Figure 1E) to a metal device (Figure 1L) that allows it to move $180^{\circ}$ around its longitudinal axis and $360^{\circ}$ around its transversal axis. In order to establish standardized points where one could check the correct position of the HS, surface marks were drawn on the metal devices (Figure $1 \mathrm{~L} ; \mathrm{M})$. 

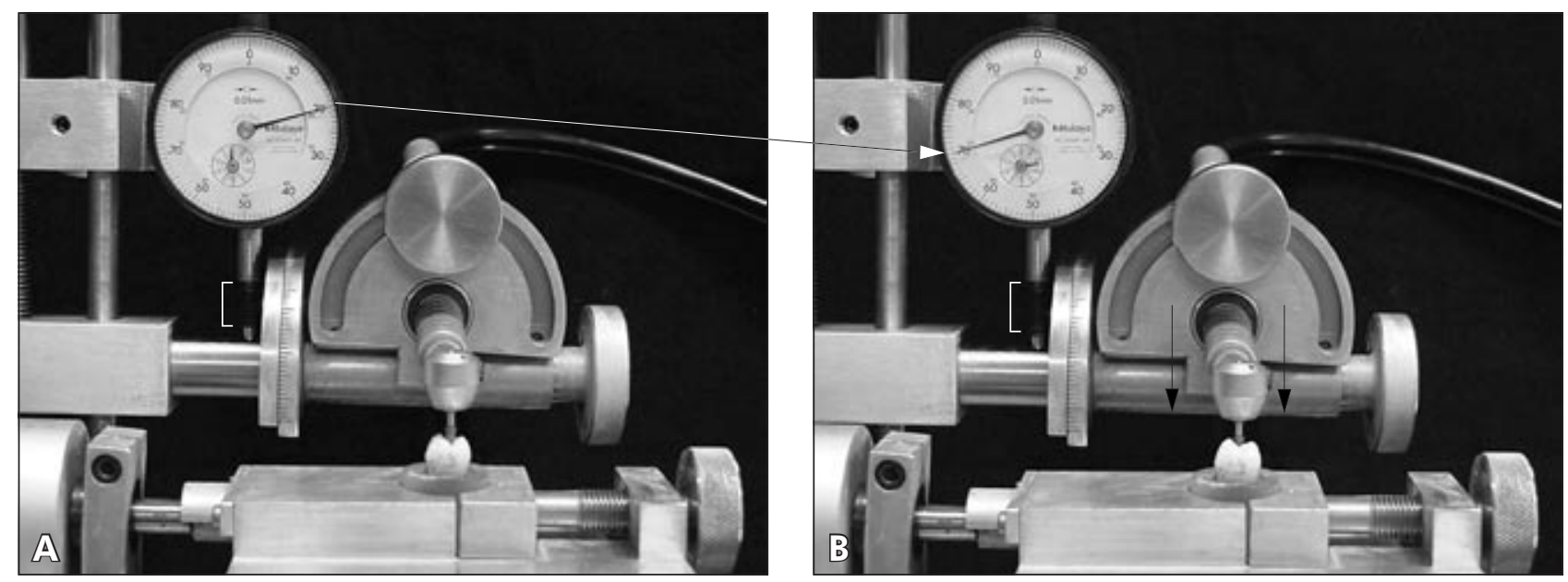

Figure 2 - Vertical movement of the handpiece. When the inferior horizontal connecting rod goes down the spring of the dial indicator (Figure $1 \mathrm{H}$ ) is uncompressed and as a result it registers the vertical movement - see "A" to "B".

A mobile table (Figure 1D), placed above the fixed table (Figure 1C), should be connected to two micrometers (Figure 1G;F) enabling horizontal movements from right to left, left to right, back to front, and front to back (see Figure 1). A metal holder (Figure $1 \mathrm{~N}$ ) on the mobile table maintains the tooth to be prepared in a steady condition. Originally, teeth must be embedded in resin cylinders to enable correct adaptation to the holder.

\section{Results}

As a result of the use of the suggested machine, an example of its use is shown right below.

\section{Example of use of the machine}

Figure 3 shows the confection of an onlay preparation with mesio-buccal cusp coverage. One freshly extracted human first mandibular molar was selected. The tooth was collected after the patient had signed an informed consent, in accordance with the ethics committee, Federal University of Uberlândia, MG, Brazil (protocol \#029/2003). In this example we used a tapered round-ended diamond bur which has $4.0 \mathrm{~mm}$ in length and $1.5 \mathrm{~mm} / 2.5 \mathrm{~mm}$ in minimum/maximum diameter (\#3131 diamond bur, KG Sorensen, Barueri, SP, Brazil). First of all, the diamond bur was attached to the HS and it was positioned at the center of the tooth's occlusal surface (Figure 2). This position needs to be recorded on the micrometer $\mathrm{H}$ (Figure $1 \mathrm{H}$ ) since it will be an initial parameter of how deep the occlusal isthmus will be. The position of the micrometer was recorded and the inferior connecting rod with the HS was positioned $2.5 \mathrm{~mm}$ above the center of the occlusal surface (Figure 2). By rolling the micrometer (Figure $1 \mathrm{~F}$ ) the HS runs from front to back (Figure 3A) and defines a $2.5 \mathrm{~mm}$-wide and $2.5 \mathrm{~mm}$-deep occlusal isthmus (Figure 3A;3B). Mesial and distal boxes were created $1.5 \mathrm{~mm}$ above the pulpal wall, and with a $1.5 \mathrm{~mm}$ deep gingival wall.

The process of cuspal coverage can be easily done by cuspal reduction following the definition of the desirable finishing line. Cuspal reduction starts by positioning the diamond bur at the top of the cusp to be prepared and recording on micrometer $\mathrm{H}$ this position. The HS connecting rod is then lowered in accordance to the amount of cusp reduction that is needed. In this case, the mesio-buccal cusp was reduced by $2.0 \mathrm{~mm}$ (Figure 3B;3C). To complete cuspal coverage, a $1.5 \mathrm{~mm}$-thick chamfer finishing line was created $1.5 \mathrm{~mm}$ below cusp reduction (Figure 3D). The prepared tooth is shown in Figure 3E.

\section{Possible modifications}

In spite of the fact that the present cavity preparation machine enables almost all sorts of preparations, some especial modifications can be performed in order to make it easier to work or more adequate 

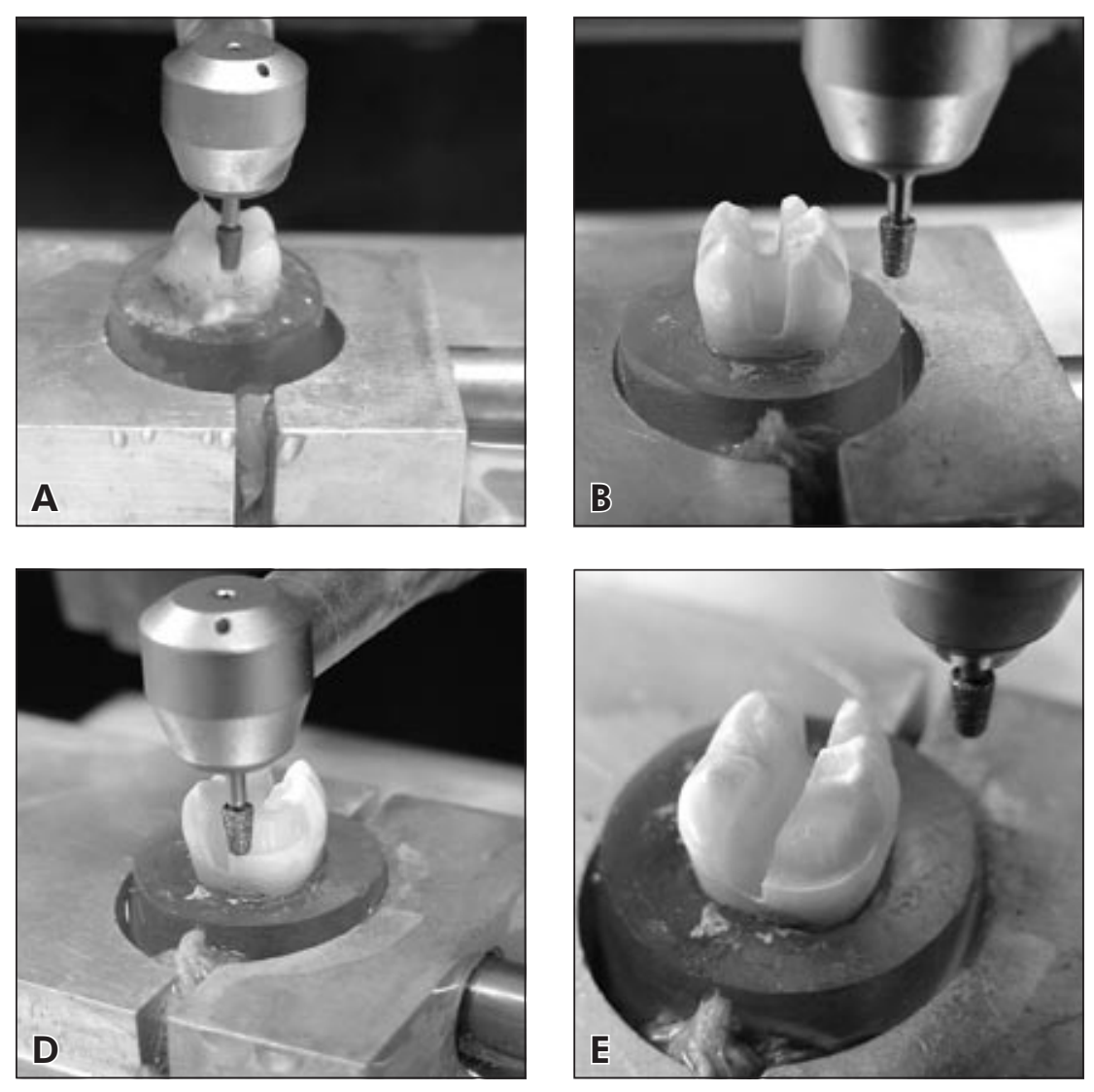

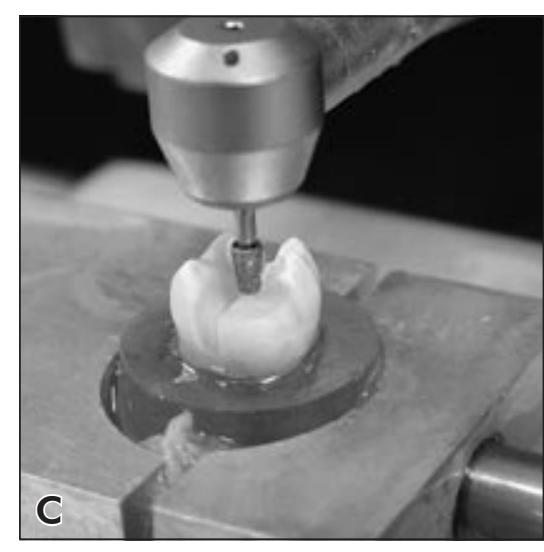

Figure 3 - Confection of an onlay preparation with mesio-buccal cusp coverage. (A) definition of a $2.5 \mathrm{~mm}$-wide and $2.5 \mathrm{~mm}$-deep occlusal isthmus. (B) occlusal, mesial and distal boxes; mesial and distal boxes were prepared $1.5 \mathrm{~mm}$ above the pulpal wall and with a $1.5 \mathrm{~mm}$-deep gingival wall. (C) mesio-buccal cusp reduced by $2.0 \mathrm{~mm}$ below the mesiobuccal cusp. (D) preparation of the $1.5 \mathrm{~mm}$-thick chamfer finishing line, $1.5 \mathrm{~mm}$ below the cuspal reduction. (E) final aspect of the prepared tooth. for a specific situation. It is possible to replace the mechanical micrometers by digital ones, which would facilitate the visualization of the quantity of movement of the mobile table. Also, replacement of the HS by a low speed one is possible, if desirable.

\section{Discussion}

When studying any variable within a research it is mandatory to search for standardization techniques in order to better answer the tested hypothesis and even more to enable more power to any conclusion. Thus, standardization of preparations, techniques and materials play an important role in the impact of research. The configuration of a cavity preparation has been of great interest to experimental and mathematical studies. Finite element analysis is a mathematical approach which can be especially indicated to study stress distribution on teeth with various preparation designs. ${ }^{12}$ When the same preparations are to be reproduced for an in vitro test it is thus extremely necessary to search for a method in which the same preparations could be confectioned in different samples. The use of a cavity preparation machine, as shown in this study, seems to be the most reliable method. Shirai et al. ${ }^{12}$ (2005) studied the effect of cavity configuration on bonding effectiveness, showing that polymerization contraction stresses can negatively affect adhesion in a high C-factor Class I cavity, for some adhesive systems. This study employed a high-speed hand piece with a cylindrical diamond bur mounted on a MicroSpecimen Former (University of Iowa, Iowa City, IA, USA) in order to create a standard box-type Class-I cavity $\left(4.5 \times 4.5 \mathrm{~mm}^{2}\right)$. Thus, the cavities should be uniform within the groups, and certainly this goal was achieved by employing the MicroSpecimen Former, a type of cavity preparation machine.

Even with the use of a method to measure the size of cavity preparations some studies employ manually prepared cavities $^{22}$ and certainly the similarity between samples is compromised. Ideally, standardization of preparations should be per- 
formed in the same device which prepares the teeth because it is possible to have instant measurement. In spite of the fact that there are studies which employ extremely accurate devices to measure preparations (0.002 mm-accuracy by Potiket et al. $\left.{ }^{22}, 2004\right)$, when measurement is performed after preparation there is a chance that it will be necessary to repeat the preparation in a new sample if tooth structure removal was excessive.

Several factors may be considered before using a cavity preparation machine. In some instances, the selection of teeth with similar size, shape and volume may possibly be the most important one. Also, pre-definition of the preparation design to be used is mandatory because it will influence the required handling characteristics of the machine and the shape of the diamond or carbide burs. In order to facilitate preparations, specific diamond/carbide burs can be newly designed, as done in this study. In the example shown in Figure 3, the \#3131 diamond bur could easily perform the expected cavity preparation. Thus, the researcher should correctly establish the preparation design to be performed and, after that, search for the specific bur which would be most indicated for it. The diamond bur used in this study allows the confection of every type of inlay and onlay preparations. Veneer and crown preparations certainly will require other types of burs.

When dealing with complex cavity preparations, inlay and onlay preparations, one of the disadvantages of the machine is that it is not possible to ensure that all internal angles will get rounded (Figure 3E), so after preparation the tooth prepara-

\section{References}

1. Ku CW, Park SW, Yang HS. Comparison of the fracture strengths of metal-ceramic crowns and three ceromer crowns. J Prosthet Dent. 2002;88(2):170-5.

2. Burke FJ. Fracture resistance of teeth restored with dentinbonded crowns: the effect of increased tooth preparation. Quintessence Int. 1996;27(2):115-21.

3. Burke FJ, Watts DC. Fracture resistance of teeth restored with dentin-bonded crowns. Quintessence Int. 1994;25(5):335-40.

4. Cho L, Choi J, Yi YJ, Park CJ. Effect of finish line variants on marginal accuracy and fracture strength of ceramic optimized tion angles will need to be manually rounded. This fact can induce variations in preparations but the use of low grit diamond burs in low speed can avoid significant alterations. Some preparation machines seem to be able to be mechanically handled instead of manually handled, as the one of this study. This is certainly an interesting characteristic, but manual handling enables control of tooth wear and this characteristic can possibly be mandatory when simulating cavity preparations for indirect restorations. The type of cavity preparation machine will be guided by both the type of study and related variables. Several studies were accomplished with the use of this machine $e^{24,26-28}$ and it is the opinion of all authors that its use was mandatory for the correct standardization of preparations. Furthermore, in order to avoid bias and methodological errors and in the search for more accurate results, a preparation machine should be employed.

\section{Conclusion}

The suggested cavity preparation machine precisely helps in the standardization of cavity preparations for in vitro studies. It is recommended that the machine be used in order to avoid incorrect interpretation of the results.

\section{Acknowledgments}

This study was supported by CNPq (Grant \#1991/157) and FAPEMIG (Grant \#154/05). This manuscript is free of conflict of interest and the authors have no financial interest in any of the mentioned companies or products.

polymer/fiber-reinforced composite crowns. J Prosthet Dent. 2004;91(6):554-60.

5. Cho L, Song H, Koak J, Heo S. Marginal accuracy and fracture strength of ceromer/fiber-reinforced composite crowns: effect of variations in preparation design. J Prosthet Dent. 2002;88(4):388-95.

6. Burke FJ, Wilson NH, Watts DC. The effect of cavity wall taper on fracture resistance of teeth restored with resin composite inlays. Oper Dent. 1993;18(6):230-6. 
7. Eakle WS, Braly BV. Fracture resistance of human teeth with mesial-occlusal-distal cavities prepared with sharp and round internal line forms. J Prosthet Dent. 1985;53(5):646-9.

8. Krejci I, Duc O, Dietschi D, de Campos E. Marginal adaptation, retention and fracture resistance of adhesive composite restorations on devital teeth with and without posts. Oper Dent. 2003;28(2):127-35.

9. Mondelli J, Steagall L, Ishikiriama A, de Lima Navarro MF, Soares FB. Fracture strength of human teeth with cavity preparations. J Prosthet Dent. 1980;43(4):419-22.

10. Jahangiri L, Wahlers C, Hittelman E, Matheson P. Assessment of sensitivity and specificity of clinical evaluation of cast restoration marginal accuracy compared to stereomicroscopy. J Prosthet Dent. 2005;93(2):138-42.

11. Sjogren G. Marginal and internal fit of four different types of ceramic inlays after luting. An in vitro study. Acta Odontol Scand. 1995;53(1):24-8.

12. Shirai K, De Munck J, Yoshida Y, Inoue S, Lambrechts P, Suzuki K et al. Effect of cavity configuration and aging on the bonding effectiveness of six adhesives to dentin. Dent Mater. 2005;21(2):110-24.

13. de Vree JH, Peters MC, Plasschaert AJ. The influence of modification of cavity design on distribution of stresses in a restored molar. J Dent Res. 1984;63(10):1217-20.

14. Magne P, Perakis N, Belser UC, Krejci I. Stress distribution of inlay-anchored adhesive fixed partial dentures: a finite element analysis of the influence of restorative materials and abutment preparation design. J Prosthet Dent. 2002;87(5):516-27.

15. Palin WM, Fleming GJ, Nathwani H, Burke FJ, Randall RC. In vitro cuspal deflection and microleakage of maxillary premolars restored with novel low-shrink dental composites. Dent Mater. 2005;21(4):324-35.

16. Belli S, Erdemir A, Ozcopur M, Eskitascioglu G. The effect of fibre insertion on fracture resistance of root filled molar teeth with MOD preparations restored with composite. Int Endod J. 2005;38(2):73-80.

17. St-Georges AJ, Sturdevant JR, Swift EJ Jr, Thompson JY. Fracture resistance of prepared teeth restored with bonded inlay restorations. J Prosthet Dent. 2003;89(6):551-7.
18. Etemadi S, Smales RJ, Drummond PW, Goodhart JR. Assessment of tooth preparation designs for posterior resin-bonded porcelain restorations. J Oral Rehabil. 1999;26(9):691-7.

19. Rasheed AA. Effect of bonding amalgam on the reinforcement of teeth. J Prosthet Dent. 2005;93(1):51-5.

20. Ortega VL, Pegoraro LF, Conti PC, do Valle AL, Bonfante G. Evaluation of fracture resistance of endodontically treated maxillary premolars, restored with ceromer or heat-pressed ceramic inlays and fixed with dual-resin cements. J Oral Rehabil. 2004;31(4):393-7.

21. Zhi-Yue L, Yu-Xing Z. Effects of post-core design and ferrule on fracture resistance of endodontically treated maxillary central incisors. J Prosthet Dent. 2003;89(4):368-73.

22. Potiket N, Chiche G, Finger IM. In vitro fracture strength of teeth restored with different all-ceramic crown systems. J Prosthet Dent. 2004;92(5):491-5.

23. Ozturk AN, Belli S, Eskitascioglu G. The in vitro effect of pulpal pressure and luting agent on tensile bond strength of complete cast crowns. J Prosthet Dent. 2004;91(3):253-7.

24. Soares CJ, Martins LR, Fernandes Neto AJ, Giannini M. Marginal adaptation of indirect composites and ceramic inlay systems. Oper Dent. 2003;28(6):689-94.

25. Sá D, Gabrielli F. Estudo da microinfiltração marginal em restaurações com amálgama. Efeito de liga, verniz e brunidura. Rev Fac Farm Odontol Ribeirão Preto. 1987;16:22-7.

26. Soares CJ, da Silva NR, Fonseca RB. Influence of the feldspathic ceramic thickness and shade on the microhardness of dual resin cement. Oper Dent. 2006;31(3):384-9.

27. Soares CJ, Martins LR, Fonseca RB, Correr-Sobrinho L, Fernandes Neto AJ. Influence of cavity preparation design on fracture resistance of posterior Leucite-reinforced ceramic restorations. J Prosthet Dent. 2006;95(6):421-9.

28. Soares CJ, Martins LR, Pfeifer JM, Giannini M. Fracture resistance of teeth restored with indirect-composite and ceramic inlay systems. Quintessence Int. 2004;35(4):281-6. 